Pacific Journal of Mathematics

REPRESENTABLE DISTRIBUTIVE NOETHER LATTICES 


\title{
REPRESENTABLE DISTRIBUTIVE NOETHER LATTICES
}

\author{
E. W. JoHnson AND J. P. LediaEV
}

\begin{abstract}
Recently, Bogart showed that a certain class of distributive Noether lattices, namely regular local ones, are embeddable in the lattice of ideals of an appropriate Noetherian ring. In this paper a characterization of the distributive Noether lattices which are representable as the complete lattice of ideals of a Noetherian ring is obtained.
\end{abstract}

We observe that if $L(R)$ is the lattice of ideals of a ring $R$ (commutative with 1) and if $A, B$ and $C$ are elements of $L(R)$ with $A \not B B$ and $A \rightrightarrows C$, then there exists a principal element $E \in L(R)$ with $E \leqq$ $A, E \nsubseteq B$ and $E \geqq C$. If a Noether lattice $L$ has this property, then we will say that $L$ satisfies the weak union condition. (The term union condition has been used elsewhere for a stronger property.) With this definition, then, the main result of this paper is that a distributive Noether lattice $L$ is representable as the lattice of ideals of a Noetherian ring if, and only if, $L$ satisfies the weak union condition.

We adopt the terminology of [2] and we assume throughout that $L$ is a Noether lattice.

Lemma 0. If $L$ is local, and if the maximal element $P \in L$ is principal, then every element $A \neq 0$ of $L$ is a power $P^{n}(0 \leqq n)$ of $P$.

Proof. If $A \neq 0$, then by the Intersection Theorem [2] there exists a largest integer $n$ such that $A \leqq P^{n}$. Then

$$
A=A \wedge P^{n}=\left(A: P^{n}\right) P^{n},
$$

so since $A \nsubseteq P^{n+1}$, it follows that $A: P^{n}=I$, and therefore that $A=P^{n}$.

Lemma 1. Assume $L$ is distributive and satisfies the weak union condition. If $L$ is local and if the maximal element of $L$ is principal, or if 0 is prime and every element $A \neq 0$ has a primary decomposition involving only powers of maximal primes, then $L$ is representable as the lattice of ideals of a Noetherian ring.

Proof. Assume $L$ is local with maximal element $P$, and that $P$ is principal. Let $(R, M)$ be a regular local ring of altitude one. If 0 is prime in $L$, then the powers of $P$ are distinct, and $L$ is isomorphic to the lattice of ideals of $R$. If 0 is not prime in $L$, and if $k$ is the least positive integer such that $P^{k}=P^{k+1}$, then $L$ is isomorphic to the lattice of ideals of $R \mid M^{k}$. 
Now, assume that 0 is prime and that every element $A \neq 0$ has a primary decomposition $P_{1}^{e_{1}} \cap \cdots \cap P_{k}^{e_{k}}$, where each $P_{i}$ is maximal. Then every prime $P \neq 0$ is maximal, so the $P_{i}$ in any decomposition $A=P_{1}^{e_{1}} \cap \cdots \cap P_{k}^{e} c_{k}$ are just the minimal primes over $A$. Since 0 is prime in $L$, it follows that distinct powers of maximal primes are distinct. Then by the comaximality of distinct primes, it follows that every element $A \neq 0$ has a factorization as a product of primes [2], and since the primes involved are maximal, the factorizations are unique.

Now, let $\alpha$ be the cardinality of the collection $\mathscr{P}$ of maximal primes in $L$, and let $K$ be a field of cardinality $\beta \geqq \alpha$. Let $A$ be a subset of $K$ of cardinality $\alpha$, and let $S$ be the complement in $K[x]$ of the union of the prime ideals $(a+x), a \in A$. Then $S$ is a multiplicatively closed subset of $K[x]$ which doesn't meet any of the prime ideals $(a+x)$, and which meets every other prime ideal. Hence $K[x]_{s}$ is a Dedekind Domain with $\alpha$ maximal primes [3].

We let $\varphi$ be a one-one correspondence between the maximal primes of $L$ and the maximal primes of $K[x]_{S}$, and extend $\varphi$ to a map of $L$ onto the lattice of ideals of $K[x]_{S}$ by taking 0 to 0 and products to products. Then since $L$ is distributive and distinct nonzero primes are comaximal, we have

$$
\begin{aligned}
& \text { (i) } \quad\left(\prod_{1}^{n} P_{i}^{e_{i}}\right) \cdot\left(\prod_{1}^{n} P_{i}^{f_{i}}\right)=\prod_{1}^{n} P_{i}^{e_{i}+f_{i}} \\
& \text { (ii) } \quad\left(\prod_{1}^{n} P_{i}^{e_{i}}\right) \wedge\left(\prod_{1}^{n} P_{i}^{f_{i}}\right)=\left(\bigwedge_{1}^{n} P_{1}^{e_{i}}\right) \wedge\left(\bigwedge_{1}^{n} P_{i}^{f_{i}}\right) \\
&=\bigwedge_{1}^{n} P_{i}^{\max \left(e_{i}, f_{i}\right)}=\prod_{1}^{n} P_{i}^{\max \left(e_{i}, f_{i}\right)}, \text { and } \\
& \text { (iii) } \quad\left(\prod_{1}^{n} P_{\imath}^{e_{i}}\right) \vee\left(\prod_{1}^{n} P_{i}^{f_{i}}\right)=\left(\bigwedge_{1}^{n} P_{i}^{e_{i}}\right) \vee\left(\bigwedge_{1}^{n} P_{i}^{f_{i}}\right) \\
&=\bigwedge_{1}^{n} P_{i}^{\min \left(e_{i}, f_{i}\right)}=\prod P_{i}^{n}{ }^{\min \left(e_{i}, f_{i}\right)},
\end{aligned}
$$

for distinct primes $P_{i}$ and for $e_{i}, f_{i} \geqq 0$.

Since the lattice of ideals of a Dedekind domain also has these properties [3], it follows that $\varphi$ is an isomorphism of $L$ onto the lattice of ideals of $K[x]_{S}$.

To reduce the general case to the cases covered by Lemma 1 , we require the following lemmas.

LEMma 2. If $L$ is distributive and satisfies the weak union condition, and if $D \in L$, then $L \mid D$ and $L_{D}$ are distributive and satisfy the weak union condition.

Proof. The proof is immediate for $L \mid D$, as is the distributivity of $L_{D}$. If $\{A\},\{B\}$ and $\{C\}$ are elements of $L_{D}$ with $\{A\} \not \equiv\{B\}$ and 
$\{A\} \geqq\{C\}$, then $A_{D} \geqq B_{D}$ and $A_{D} \geqq C_{D}$. So there exists a principal element $E \in L$ with $E \leqq A_{D}, E \leqq B_{D}$ and $E \geqq C_{D}$. Then $\{E\}$ is principal with $\{E\} \leqq\{A\},\{E\} \geqq\{B\}$ and $\{E\} \leqq\{C\}$.

LEMMA 3. If $L$ is a distributive local Noether lattice which satisfies the weak union condition, then the maximal element $P$ of $L$ is principal.

Proof. Let $A_{1}, \cdots, A_{k}$ be a minimal collection of principal elements with join $P$. If $k>1$, then $P \geqq A_{1} \vee \cdots \vee A_{k-1}$ and $P \geqq A_{k}$, so there exists a principal element $A \leqq P$ with $A \not A_{1} \vee \cdots A_{k-1}$ and $A \supsetneqq A_{k}$. Then

$$
\begin{aligned}
A= & A \wedge P=A \wedge\left[\left(A_{1} \vee \cdots \vee A_{k-1}\right) \vee A_{k}\right] \\
& =\left(\left(A_{1} \vee \cdots \vee A_{k-1}\right) \wedge A\right) \vee\left(A_{k} \wedge A\right) \\
& =\left(\left(A_{1} \vee \cdots \vee A_{k-1}\right): A \vee\left(A_{\kappa}: A\right)\right) A .
\end{aligned}
$$

Since $A \neq 0$, it follows from the Intersection Theorem [2] that

$$
\left(A_{1} \vee \cdots \vee A_{k-1}\right): A \vee A_{k}: A=I,
$$

which is a contradiction since $L$ is local. Hence $k=1$.

We are now ready to prove the following

Theorem 4. If $L$ is a distributive Noether lattice, then $L$ is representable as the lattice of ideals of a Noetherian ring if and only if, $L$ satisfies the weak union condition.

Proof. Since the lattice of ideals of any ring satisfies the weak union condition, the "only if" is clear. Hence, assume $L$ is a distributive Noether lattice which satisfies the weak union condition. Let

$$
0=Q_{1} \cap \cdots \cap Q_{s} \cap \cdots \cap Q_{k}
$$

be a normal decomposition of 0 in which $Q_{i}$ is $P_{i}$-primary. We assume that $P_{1}, \cdots, P_{s}$ are nonmaximal elements of $L$ and that $P_{s+1}, \cdots, P_{k}$ are maximal.

By Lemmas 2 and 3 and the Principal Ideal Theorem [2], if $P$ is any prime in $L$, then $P$ has height no greater than one, so every prime is either maximal or minimal. Further, if $P^{\prime}<P$ are primes, then by Lemma 0,0 is prime in $L_{P}$, so $O_{P}=P^{\prime}=\Lambda_{1}^{\infty} P^{n}$. It follows from this that 0 has no embedded primes, that the primaries $Q_{i}, 1 \leqq i \leqq s$, are the $P_{i}$, and that no prime $P$ contains two distinct minimal primes. Further, since every element, except possibly 0 , of $L_{P}$ is a power of the maximal element, we have that the $P$-primary elements of the 
maximal primes $P$ are precisely the powers $P^{n}$ of $P$.

Then for each $i, s+1 \leqq i \leqq k$, there exists a positive integer $e_{i}$ with $Q_{i}=P_{i}^{e_{i}}$. Hence $0=P_{1} \cap \cdots \cap P_{s} \cap P_{s+1}^{e_{s+1}} \cap \cdots \cap P_{k}^{e_{k}}$. Then since the $P_{i}$ are pairwise comaximal we have

$$
L \cong L\left|P_{1} \oplus \cdots \oplus L\right| P_{s} \oplus L\left|P_{s+1}^{e_{s}+1} \oplus \cdots \oplus L\right| P_{k}^{e_{k}},
$$

where each summand is of the type considered in Lemma 1.

Since the lattice of ideals of a direct sum $R_{1} \oplus \cdots \oplus R_{n}$ of rings is isomorphic to the direct sum of the lattices of ideals of the rings, the result now follows.

It is easily seen from the decomposition

$$
L \cong L\left|P_{1} \oplus \cdots \oplus L\right| P_{s} \oplus L\left|P_{s+1}^{e_{s}+1} \oplus \cdots \oplus L\right| P_{k}^{e_{k}},
$$

in the proof of Theorem 4 that every element of $L$ is a product of primes and that the maximal elements of $L$ are meet principal (in fact that every element is principal). Also, it is seen that the decomposition above characterizes the distributive Noether lattices which are representable as the lattice of ideals of a Noetherian ring. These observations lead to the following theorem which is stated without proof since the proof is similar to that of Theorem 4 .

THEOREM 5. The following are equivalent for a Noether lattice L:

(i) $L$ is distributive and representable as the lattice of ideals of a Noetherian ring

(ii) $L$ is distributive and satisfies the weak union condition

(iii) For every maximal element $P, L_{P}$ is linear

(iv) Every element $A$ of $L$ different from $I$ is a product of primes

(v) Every maximal element $P$ of $L$ satisfies the condition $A \wedge$ $P=(A: P) P$, for all $A$ in $L$

(vi) $L$ is the direct sum $L=L_{1} \oplus \cdots \oplus L_{n}$ of Noether lattices $L_{i}$, where for each $i$, either $L_{i}$ is local with a principal maximal element, or 0 is prime in $L_{i}$ and every element $A \neq I$ is a (unique) product of primes.

\section{REFERENCES}

1. K. P. Bogart, Structure theorem for regular local Noether lattices, Mich. J. Math. 15 (1968), 167-176.

2. R. P. Dilworth, Abstract commutative ideal theory, Pacific J. Math. 12 (1962), 481498.

3. O. Zariski, and P., Samuel, Commutative algebra, I, D. Van Nostrand Co., Inc., Princeton.

Received January 15, 1968.

UNIVERSITY OF IOWA 


\section{PACIFIC JOURNAL OF MATHEMATICS}

\section{EDITORS}

\author{
H. ROYDEN \\ Stanford University \\ Stanford, California \\ R. R Phelps \\ University of Washington \\ Seattle, Washington 98105
}

\author{
J. Dugundui \\ Department of Mathematics \\ University of Southern California \\ Los Angeles, California 90007
}

RICHARD ARENS

University of California

Los Angeles, California 90024

\section{ASSOCIATE EDITORS}
E. F. BeCKENBACH
B. H. NeUmanN
F. WolF
K. YosidA

\section{SUPPORTING INSTITUTIONS}

\author{
UNIVERSITY OF BRITISH COLUMBIA \\ CALIFORNIA INSTITUTE OF TECHNOLOGY \\ UNIVERSITY OF CALIFORNIA \\ MONTANA STATE UNIVERSITY \\ UNIVERSITY OF NEVADA \\ NEW MEXICO STATE UNIVERSITY \\ OREGON STATE UNIVERSITY \\ UNIVERSITY OF OREGON \\ OSAKA UNIVERSITY \\ UNIVERSITY OF SOUTHERN CALIFORNIA
}

\author{
STANFORD UNIVERSITY \\ UNIVERSITY OF TOKYO \\ UNIVERSITY OF UTAH \\ WASHINGTON STATE UNIVERSITY \\ UNIVERSITY OF WASHINGTON

$* * * * *$
AMERICAN MATHEMATICAL SOCIETY
CHEVRON RESEARCH CORPORATION
TRW SYSTEMS
NAVAL WEAPONS CENTER

The Supporting Institutions listed above contribute to the cost of publication of this Journal, but they are not owners or publishers and have no responsibility for its content or policies.

Mathematical papers intended for publication in the Pacific Journal of Mathematics should be in typed form or offset-reproduced, double spaced with large margins. Underline Greek letters in red, German in green, and script in blue. The first paragraph or two must be capable of being used separately as a synopsis of the entire paper. It should not contain references to the bibliography. Manuscripts, in duplicate if possible, may be sent to any one of the four editors. Please classify according to the scheme of Math. Rev. 36, 1539-1546. All other communications to the editors should be addressed to the managing editor, Richard Arens, University of California, Los Angeles, California, 90024.

50 reprints are provided free for each article; additional copies may be obtained at cost in multiples of 50 .

The Pacific Journal of Mathematics is published monthly. Effective with Volume 16 the price per volume (3 numbers) is $\$ 8.00$; single issues, $\$ 3.00$. Special price for current issues to individual faculty members of supporting institutions and to individual members of the American Mathematical Society: $\$ 4.00$ per volume; single issues $\$ 1.50$. Back numbers are available.

Subscriptions, orders for back numbers, and changes of address should be sent to Pacific Journal of Mathematics, 103 Highland Boulevard, Berkeley, California, 94708.

PUBLISHED BY PACIFIC JOURNAL OF MATHEMATICS, A NON-PROFIT CORPORATION

Printed at Kokusai Bunken Insatsusha (International Academic Printing Co., Ltd.), 7-17. Fujimi 2-chome, Chiyoda-ku, Tokyo, Japan. 


\section{Pacific Journal of Mathematics}

Vol. 28, No. 3

May, 1969

Jon F. Carlson, Automorphisms of groups of similitudes over $F_{3} \ldots \ldots \ldots$

W. Wistar (William) Comfort, Neil Hindman and Stelios A. Negrepontis,

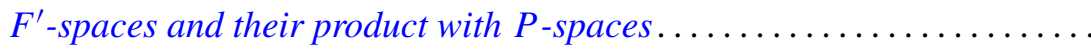

Archie Gail Gibson, Triples of operator-valued functions related to the unit

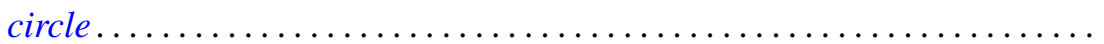

David Saul Gillman, Free curves in $E^{3}$

E. A. Heard and James Howard Wells, An interpolation problem for

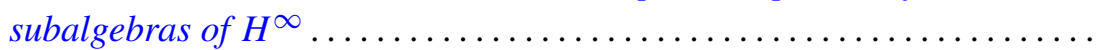

Albert Emerson Hurd, A uniqueness theorem for weak solutions of symmetric

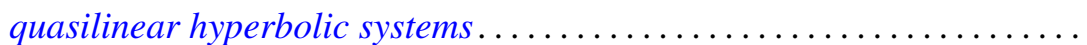

E. W. Johnson and J. P. Lediaev, Representable distributive Noether

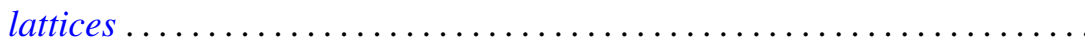

David G. Kendall, Incidence matrices, interval graphs and seriation in

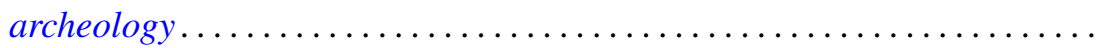
565

Robert Leroy Kruse, On the join of subnormal elements in a lattice ....... 571

D. B. Lahiri, Some restricted partition functions; Congruences modulo 3 .... 575

Norman D. Lane and Kamla Devi Singh, Strong cyclic, parabolic and conical differentiability........................................

William Franklin Lucas, Games with unique solutions that are

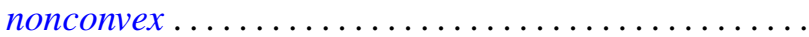

Eugene A. Maier, Representation of real numbers by generalized geometric series.

Daniel Paul Maki, A note on recursively defined orthogonal polynomials ...

Mark Mandelker, $F^{\prime}$-spaces and z-embedded subspaces ...

James R. McLaughlin and Justin Jesse Price, Comparison of Haar series with gaps with trigonometric series

Ernest A. Michael and A. H. Stone, Quotients of the space of irrationals ....

William H. Mills and Neal Zierler, On a conjecture of Golomb ...

J. N. Pandey, An extension of Haimo's form of Hankel convolutions ...

Terence John Reed, On the boundary correspondence of quasiconformal mappings of domains bounded by quasicircles...

Haskell Paul Rosenthal, A characterization of the linear sets satisfying Herz's criterion.

George Thomas Sallee, The maximal set of constant width in a lattice...

I. H. Sheth, On normaloid operators

James D. Stasheff, Torsion in BBSO ...

Billy Joe Thorne, A - P congruences on Baer semigroups.

Robert Breckenridge Warfield, Jr., Purity and algebraic compactness for

modules... 